\title{
Wnt/及-Catenin Signaling Contributes to Vincristine-Induced Neuropathic Pain
}

\author{
Chuanyin $\mathrm{HU}^{1^{*}}$, Yun-Tao ZHAO ${ }^{2 *}$, Yan-Bing CUI ${ }^{3}$, Hua-Hua ZHANG ${ }^{1}$, Geng-Li HUANG ${ }^{2}$, \\ You LIU ${ }^{2}$, Yan-Fen LIU $^{3,2}$ \\ *These authors contributed equally to this work. \\ ${ }^{1}$ Department of Biology, Guangdong Medical University, Zhanjiang, Guangdong, China, \\ ${ }^{2}$ Department of Bioengineering, College of Food Science, Guangdong Ocean University, Zhanjiang, \\ Guangdong, China, ${ }^{3}$ College of Agriculture, Guangdong Ocean University, Zhanjiang, Guangdong, \\ China
}

Received September 17, 2019

Accepted June 9, 2020

Epub Ahead of Print June 25, 2020

\begin{abstract}
Summary
Chemotherapy-induced neuropathic pain (CNP) is the major dose-limiting factor in cancer chemotherapy. However, the mechanisms underlying CNP remain elusive. In the present study, CNP was induced by repeated intraperitoneal injection of vincristine (VCR) into male C57BL/6] mice. VCR administration caused significant activation of $\mathrm{Wnt} / \beta$-catenin signaling, which led to the activation of astrocytes, microglia, the release of inflammatory cytokines tumor necrosis factor (TNF)-a, monocyte chemoattractant protein-1 (MCP-1) and the activation of subsequent mitogen-activated protein kinase (MAPK)/extracellular signal-regulated protein kinase (ERK) signaling pathway in CNP mice. Blocking Wnt/ $\beta$-catenin signaling by intrathecal administration of the inhibitors of Wnt response (IWR) effectively attenuated VCR-induced neuropathic pain. Furthermore, IWR inhibited the activation of astrocytes, microglia, TNF-a, MCP-1 and MAPK/ERK signaling in the spinal cord, which was triggered by VCR-induced Wnt/ $\beta$-catenin signaling upregulation. These results suggest that $\mathrm{Wnt} / \beta$-catenin signaling plays a critical role in VCR-induced neuropathic pain and provides evidence for potential interfering with $W n t / \beta$-catenin signaling to ameliorate VCR-induced neuropathic pain.
\end{abstract}

\section{Key words}

Wnt/ $\beta$-catenin signaling • Chemotherapy-induced neuropathic pain • Vincristine • Inflammation • MAPK/ERK signaling

\section{Corresponding authors}

You Liu, Department of Bioengineering, College of Food Science, Guangdong Ocean University, 1 Hai-Da Road, Zhanjiang, Guangdong 524088, China. E-mail: liuy6254282@163.com. Yan-Fen Liu, College of Agriculture, Guangdong Ocean University, 1 Hai-Da Road, Zhanjiang, Guangdong, 524088, China. E-mail: lyf201809@163.com

\section{Introduction}

Vincristine (VCR) is a widely used chemotherapeutic drug. Peripheral neuropathy is the major dose-limiting adverse effect of VCR and can lead to dose reduction or even discontinuation of treatment, thus impacting the quality of life of patients with cancer (Dougherty et al. 2007). However, the mechanisms underlying the pathophysiology of neuropathic pain are unknown, and an effective therapeutic strategy to control this pain disorder is not available at present.

Wnts are secreted glycoproteins that play important roles in the development of the central nervous system (CNS), including neural induction and patterning, cell proliferation, cell fate specification, cell polarization, cell migration, axon guidance and synaptogenesis (Park and Shen 2012, Ciani and Salinas 2005). In addition, Wnt signaling in adult organisms modulates tissue regeneration and homeostasis in several organs as well as plasticity and disease pathophysiology in the adult CNS (Grigoryan et al. 2008, MacDonald et al. 2009). There 
are three well-known Wnt signaling pathways, namely, the canonical Wnt/ $\beta$-catenin pathway, the non-canonical planar cell polarity pathway and the $\mathrm{Wnt} / \mathrm{Ca}^{2+}$ pathway (Speese and Budnik 2007). The Wnt/ $\beta$-catenin signaling pathway has been reported to play crucial roles in the pathogenesis of various types of pain, including peripheral nerve injury-induced pain, multiple sclerosisassociated chronic pain, HIV-associated chronic pain, bone cancer pain and diabetic peripheral neuropathy (Itokazu et al. 2014, Tang et al. 2018, Yuan et al. 2012, Shi et al. 2013, Zhang et al. 2013, Resham and Sharma 2019). However, whether it participates in chemotherapyinduced neuropathic pain (CNP) is unknown.

The present study aimed to elucidate the impact of the Wnt/ $\beta$-catenin signaling pathway in CNP and investigate the ameliorating effect of a Wnt-signaling inhibitor in CNP. The results indicated that the spinal activation of Wnt/ $\beta$-catenin signaling induced by VCR triggered glial cell and MAPK/ERK signaling activation, as well as the stimulation and release of the inflammatory factors TNF- $\alpha$ and MCP-1. Thus, the pharmacological inhibition of $\mathrm{Wnt} / \beta$-catenin signaling may be useful to treat CNP.

\section{Methods}

\section{Animals}

Male SPF C57BL/6J mice (7-8 weeks old, 20-25 g) were obtained from Guangdong Medical Laboratory Animal Center. All animals were housed under standard conditions in a room on a 12-h light/dark cycle with access to food and water ad libitum. All animal studies were conducted in accordance with the principles and procedures outlined in the Guide for the Care and Use of Laboratory Animals, and the protocols were approved by the Laboratory Animal Ethics Committee of Guangdong Medical University (4408030012616).

\section{Induction of neuropathic pain by $V C R$}

VCR (Guangdong Lingnan Pharmaceutical Co., Ltd.) was dissolved in normal saline and injected at $0.1 \mathrm{mg} / \mathrm{kg} /$ day intraperitoneally (i.p.) for two 5-day cycles with a 2-day pause between the cycles (days 0-4 and 7-11). The dose of VCR was selected according to a previous report (Kiguchi et al. 2008). Mice receiving VCR were considered as the VCR group. Control mice were injected with normal saline according to the same schedule.

\section{Intrathecal administration}

Animals were i.p. anesthetized with $50 \mathrm{mg} / \mathrm{kg}$ sodium pentobarbital. A polyethylene (PE)-10 tube (BD, Biosciences) was inserted into the lumbar subarachnoid space between the L4-L5 vertebrae as previously described ( $\mathrm{Wu}$ et al. 2004). To verify whether the intrathecal catheter implantation was correct, $2 \%$ lidocaine $(10 \mu \mathrm{l})$ was injected intrathecally. Those mice exhibiting complete hind limb paralysis were used for the following experiments. At the end of each experiment, the position of the PE tube in the intrathecal space at the lumbar enlargement was visually verified by exposing the lumbar spinal cord. IWR-1-endo (IWR), an effective inhibitor of the $\mathrm{Wnt} / \beta$-catenin signaling pathway, was purchased from Santa Cruz Biotechnology, Inc. IWR was dissolved in $2 \%$ dimethyl sulfoxide (DMSO)/PBS. VCR mice were administered with IWR once a day between days 11 and 17 (IWR group). VCR mice were treated with vehicle (10 $\mu 12 \% \mathrm{DMSO} / \mathrm{PBS})$ daily from day1 1 to 17 (Vehicle group).

\section{Experimental design}

CNP mice model was made by intraperitoneal injection of VCR. To clarify whether Wnt/ $\beta$-catenin signaling pathway participates in the pathogenesis of $\mathrm{CNP}$ and potential molecular mechanisms of $\mathrm{Wnt} / \beta$ catenin signaling in CNP, we checked expression of $\mathrm{Wnt} / \beta$-catenin signaling related molecules, glia cells, inflammatory factors and components of MAPK signaling pathway, such as ERK1/2, which are controlled by Wnt signaling at $\mathrm{d} 11$. To further exemplify the effects of $\mathrm{Wnt} / \beta$-catenin signaling in $\mathrm{CNP}$, the $\mathrm{Wnt} / \beta$-catenin pathway inhibitor IWR was intrathecally administrated for 7 days from day 11 to day 17 . At d18, the second day of the last administration of IWR, the related experiments were performed. Moreover, behavioral tests were carried out from 9 to 11 a.m. on certain day in general. Mice were usually euthanized from 2:30 to 5:30 p.m. on certain day for different experiments.

In our experiments, mice were divided into Control group, VCR group, Vehicle group and IWR group ( $\mathrm{n}=18$ in each group). In the first series of experiments, mice in Control group were sacrificed at day 11, whereas mice in VCR group were sacrificed on $11 \mathrm{~d}$ and $18 \mathrm{~d}$. Then the spinal cords were rapidly harvested and preserved for Western blot analysis of Wnt3a and $\beta$-catenin ( $n=3$ in Control group, $n=3 / d$ in VCR group).

In the second series of experiments, the baseline measurements of pain behavior were made prior to drug 
treatment. Pain behavioral tests were performed at days -1 , $4,7,11,15,18,21,24$ after VCR treatment (in the four groups, $n=10$ before day $15 ; n=6 \sim 7$ after day 11 just as some mice have been sacrificed for certain study at day 11).

In the third series of experiments, immunofluorescence of GFAP and IBA-1 was performed at day 11 in the spinal cord sections of Control and VCR group, whereas which was carried out at day 18 in the spinal cord sections of Vehicle and IWR group $(n=3$ in each group).

In the fourth series of experiments, the spinal cords of mice were harvested for detection of content of TNF- $\alpha$ and MCP-1 on 11d in Control and VCR group $(n=4)$. Mice of VCR group were intrathecally administered with IWR or vehicle from $11 \mathrm{~d}$ to $17 \mathrm{~d}$. Then ELISA of TNF- $\alpha$ and MCP-1was carried out in the spinal cords of Vehicle and IWR mice on $18 \mathrm{~d}(\mathrm{n}=4)$.

In the fifth series of experiments, mice in Control and VCR group were sacrificed on 11d and the spinal cords were harvested and preserved for Western blot analysis of $\mathrm{p}$-ERK1/2 $(\mathrm{n}=3)$. The detection of spinal content of p-ERK $1 / 2$ in Vehicle and IWR mice was performed on $18 \mathrm{~d}(\mathrm{n}=3)$.

\section{Mechanical paw withdrawal test}

Mice were accustomed to the test environment daily for 2 days before baseline testing. The room temperature and humidity was maintained stable during the experiment. To assess mechanical sensitivity, mice were placed in boxes on a wire mesh for $30 \mathrm{~min}$ prior to testing. Von Frey filaments (0.02-2.56 g; Stoelting, Co.) were applied to the plantar surface of each hind paw. The $50 \%$ paw withdrawal threshold (PWT) was calculated by the up-down method (Chaplan et al. 1994).

\section{Western blot analysis}

Western blotting was performed according to our previous study (Hu et al. 2014). Simply, mice were deeply anesthetized with sodium pentobarbital $(50 \mathrm{mg} / \mathrm{kg}$, i.p.) and then rapidly sacrificed by decapitation. The L4-L6 spinal cord was removed immediately on an ice-cold plate, frozen, and stored at $-80^{\circ} \mathrm{C}$ until used. Samples were homogenized in an SDS sample buffer containing a mixture of proteinase and phosphatase inhibitors (Sigma-Aldrich; Merck KGaA). The protein concentration was examined by the bicinchoninic acid method. Proteins (30 $\mu \mathrm{g} /$ sample) were separated by $10 \%$ SDS-PAGE and transferred to nitrocellulose membranes. The membranes were then blocked in $10 \%$ skimmed milk for $1 \mathrm{~h}$ at room temperature and probed with the following primary antibodies overnight at $4{ }^{\circ} \mathrm{C}$ : Rabbit anti-Wnt3a (1:2,000; Cat. no. ABD124; Chemicon International; Thermo Fisher Scientific, Inc.), mouse anti$\beta$-catenin (1:1,000; cat. no. BD 610153; BD Biosciences), rabbit anti-phosphorylated (p)-ERK $(1: 1,000$; cat. no. 3192; Cell Signaling Technology, Inc.) and mouse anti- $\beta$ actin (1:3,000; cat. no. A1978; Sigma-Aldrich; Merck $\mathrm{KGaA}$ ). Membranes were further incubated with an HRP conjugated secondary antibody for $1 \mathrm{~h}$ at room temperature and rinsed 3 times (10 min each) with TBS. The bands were visualized by enhanced chemiluminescence detection. The densities of the protein blots were analyzed using ImageJ software. Target protein densitometry values were adjusted to $\beta$-tubulin intensity and normalized to the expression level of the control sample.

\section{Immunofluorescence}

Mice were terminally anesthetized with sodium pentobarbital (50 mg/kg, i.p.) and perfused transcardially with PBS followed by $4 \%$ paraformaldehyde (PFA). The segments of spinal cord (L4-L5) were harvested, postfixed overnight in $4 \%$ PFA and dehydrated in $30 \%$ sucrose at $4^{\circ} \mathrm{C}$. Spinal cord sections $(20 \mu \mathrm{m}$ in thickness $)$ were prepared with a cryostat (Leica). The sections were blocked for $2 \mathrm{~h}$ at room temperature with $10 \%$ horse serum in $0.3 \%$ Triton X-100 and incubated overnight at $4{ }^{\circ} \mathrm{C}$ with the indicated primary antibodies: mouse antiGFAP (1:600; cat. no. MAB360; EMD Millipore) and rabbit anti-IBA-1 (1:300; cat. no. 019-19741; Wako, Pure Chemical Industries, Ltd.). The sections were incubated with FITC-conjugated secondary antibodies (1:1,000; Jackson ImmunoResearch Laboratories, Inc.) for $2 \mathrm{~h}$ at room temperature. Fluorescence images were obtained with a Leica fluorescence microscope (Leica Microsystems, Inc.). To obtain quantitative measurements, the immunofluorescence intensity of GFAP and IBA-1, 12 spinal cord sections from each group ( $\mathrm{n}=3$ mice) were evaluated and photographed under equal exposure time to obtain the raw data. The fluorescence images were transformed into 8-bit grey images and subsequently inverted to black (GFAP ${ }^{+}$, IBA- $1^{+}$) and white images. After background subtraction, the mean density of each section was measured by ImageJ software (National Institutes of Health).

\section{ELISA}

The left dorsal horns of the L4-L5 spinal 
segments of mice in different groups were split in accordance with the same method used for Western blot analysis. The amounts of TNF- $\alpha$ and MCP-1 was measured by ELISA kits for mouse protein according to the manufacturer's instructions (MTA00B for TNF- $\alpha$ and MJE00 for MCP-1; both from R\&D Systems, Inc.). Values were expressed as pictogram per mg protein.

\section{Statistical analysis}

Data are presented as means \pm standard error of the mean. Behavioral data were analyzed by two-way repeated measures analysis of variance (ANOVA). One-way ANOVA followed by Bonferroni test was used to evaluate the significant differences in the group data in experiments of Western blot, immunofluorescence and ELISA. All statistical analyses were performed using SPSS 13.0 (SPSS, Inc.). $\mathrm{P}<0.05$ was considered to indicate a statistically significant difference.

\section{Results}

$V C R$ injection activates $W n t / \beta$-catenin signaling in the spinal cord

To clarify whether $\mathrm{Wnt} / \beta$-catenin signaling participates in the pathogenesis of VCR-induced neuropathic pain, the present study first detected the protein expression of $\mathrm{Wnt3a}$, a well-characterized activator of the $\mathrm{Wnt} / \beta$-catenin signaling pathway, by Western blotting. As shown in Figure 1, the Wnt3a protein level was significantly increased in the lumbar spinal cord. Compared with that in the Control group, Wnt3a expression was enhanced by $1.72 \pm 0.16$-fold and $1.91 \pm 0.12$-fold at days 11 and 18 , respectively, in VCR-treated mice. Next, the lumbar spinal cord expression of $\beta$-catenin, a key downstream effector in the canonical Wnt/ $\beta$-catenin signaling pathway, was evaluated. The results revealed a marked upregulation of $\beta$-catenin expression at days 11 and 18 in the spinal cord of the VCR-treated mice in contrast to that observed in the control animals. Our analysis indicated that the Wnt/ $\beta$-catenin signaling pathway was activated by VCR injection in the spinal cord.

$W n t / \beta$-catenin signaling contributes to the maintenance of VCR-induced neuropathic pain

These preliminary results suggest that $\mathrm{Wnt} / \beta$-catenin signaling may participate in the maintenance of VCR-induced neuropathic pain. To clarify this, the classical Wnt/ $\beta$-catenin signaling pathway inhibitor IWR
(Zhang et al. 2013) was administered intrathecally to the mice for 7 days, from day 11 to 17 . IWR generated longlasting inhibitory effects on the existed mechanical allodynia (Fig. 2). These findings indicated that the activation of $\mathrm{Wnt} / \beta$-catenin signaling in the spinal cord contributed to the maintenance of VCR-induced neuropathic pain.

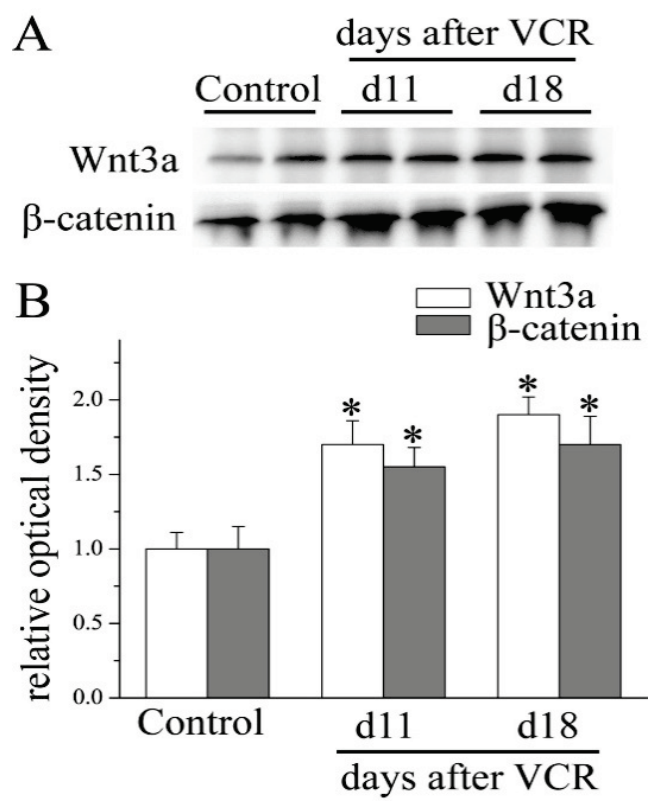

Fig. 1. VCR administration activated spinal $W n t / \beta$-catenin signaling. Western blotting demonstrated an increase in Wnt3a and $\beta$-catenin protein at days 11 and 18 in mouse spinal cord after VCR treatment $\left({ }^{*} \mathrm{P}<0.05\right.$ versus Control group; one-way ANOVA with Bonferroni test; $n=3$ ). VCR, vincristine.

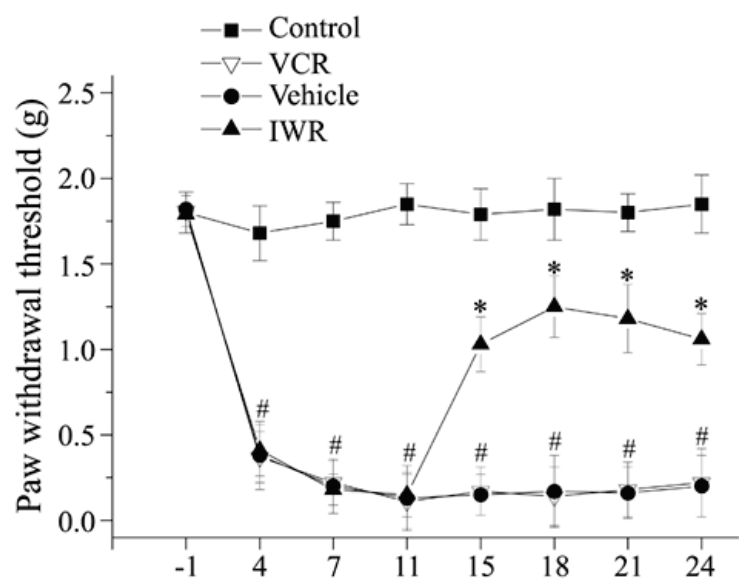

Fig. 2. Inhibition of $W n t / \beta$-catenin signaling alleviated mechanical allodynia induced by VCR. Hind paw withdrawal threshold for mechanical stimulation by von Frey filaments was measured at days $1,4,7,11,15,18,21,24$ after VCR treatment (in the four groups, $\mathrm{n}=10$ before day $15 ; \mathrm{n}=6 \sim 7$ after day 11 just as some mice have been sacrificed for certain study at day 11). After VCR injection, mice showed prominently reduced paw withdrawal thresholds, indicating the presence of tactile allodynia. IWR-1 reversed VCR-induced mechanical allodynia ( $\# \mathrm{P}<0.05$ versus Control group, $* \mathrm{P}<0.05$ versus Vehicle group; two-way ANOVA). 
Wnt/ $\beta$-catenin signaling inhibition suppresses VCR-induced astrocytic and microglial activation in the dorsal horn

It was hypothesized that a correlation existed between Wnt signaling and glia-mediated neuroinflammation under the pathological condition of neuropathic pain. IWR ameliorated pain through inhibiting spinal glial activation (Itokazu et al. 2014, Marchetti and Pluchino 2013, Shen et al. 2015). The present study evaluated the expression of the astrocytic marker GFAP in the spinal cord after VCR amdinistration. Immunofluorescence revealed that, compared with that of the Control group, GFAP staining was markedly enhanced in the spinal cord of the VCR group at day 11 post-VCR administration. Compared with that observed in the Vehicle group, IWR inhibited the VCR-induced increase in GFAP immunoreactivity in the dorsal horn at day 18 following VCR administration (Fig. 3A-E). Our results indicated that inhibition of Wnt/ $\beta$-catenin signaling decreased VCR-induced astrocytic activation in the spinal cord. Furthermore, the activation of microglia in the spinal cord was examined. As shown in Figure $3 \mathrm{~A}^{\prime}-\mathrm{E}^{\prime}$, the staining of IBA-1 increased by $\sim 3$-fold at day 11 after VCR administration. Similarly, the intensity of IBA-1 immunoreactivity was also considerably declined by IWR. Our findings suggested that IWR administration also reduced microglial activation, which was induced by VCR, in the dorsal horn.
GFAP
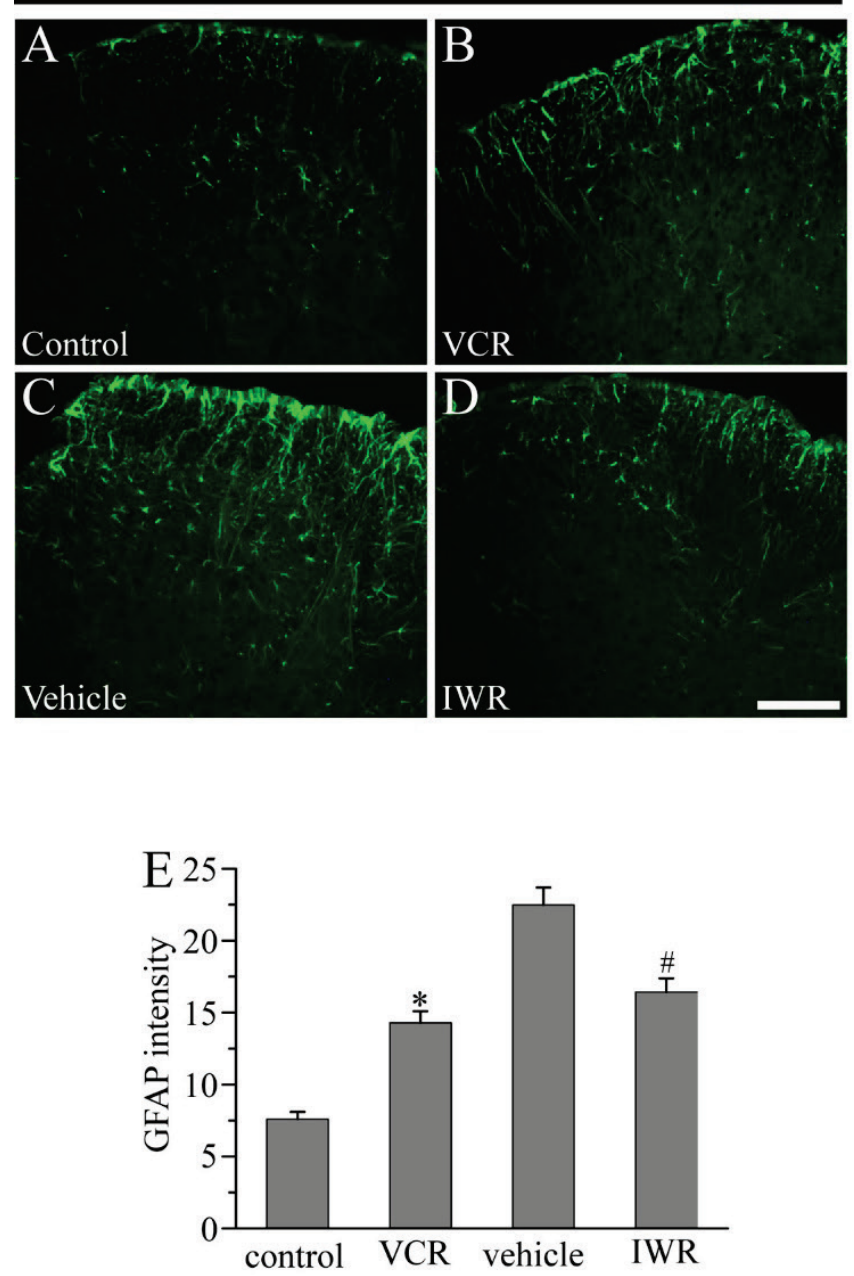

IBA-1
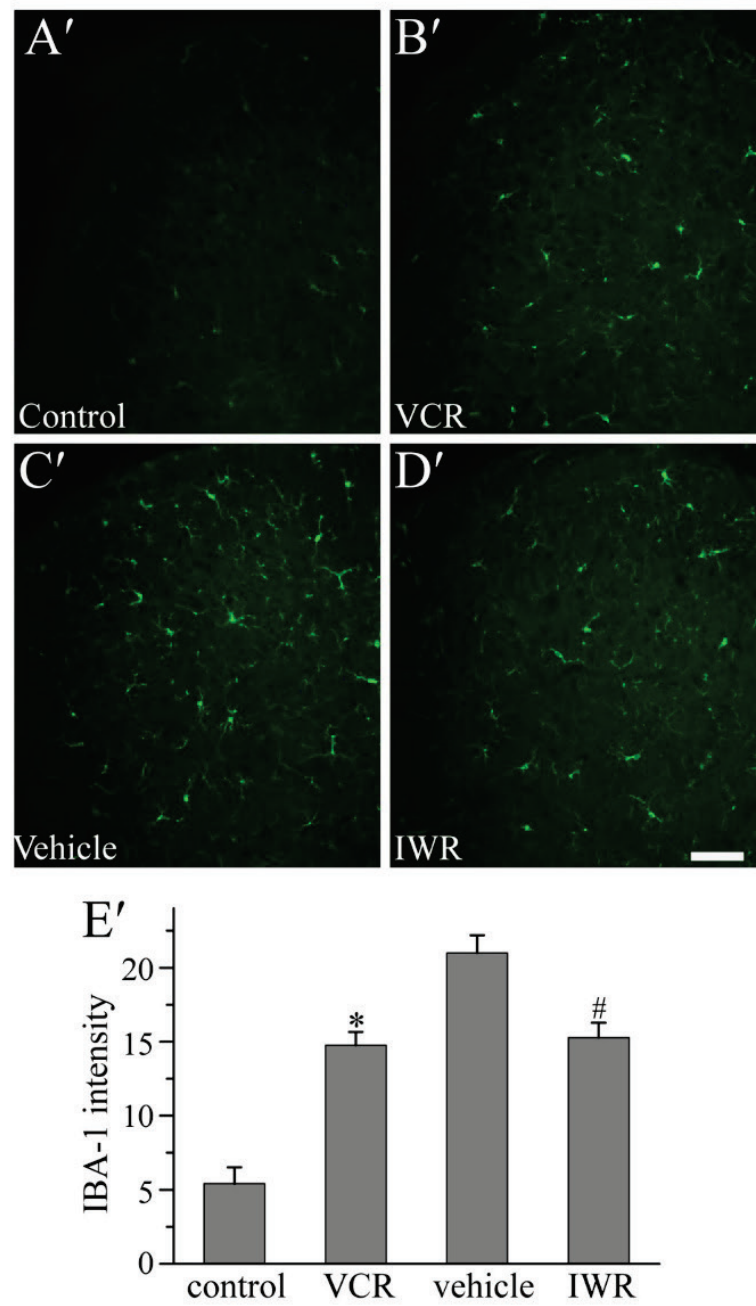

Fig. 3. IWR attenuated the activation of astrocytes and microglia induced by VCR. (A-B; $\left.A^{\prime}-B^{\prime}\right)$ : Compared with the Control group, GFAP and IBA-1 staining was enhanced in the spinal cord at day 11 in VCR-treated mice. (C-D; $\left.C^{\prime}-D^{\prime}\right)$ : GFAP and IBA-1 immunoreactivity was reduced after IWR treatment at day 18. Scale bar: $200 \mu \mathrm{m}$. (E, $\left.E^{\prime}\right)$ : Quantitative determination of the GFAP and IBA-1 immunostaining shown in $(A-D)$ and $\left(A^{\prime}-D^{\prime}\right)$ respectively $(* P<0.05$ versus Control group, $\# P<0.05$ versus Vehicle group; one-way ANOVA with Bonferroni test; $n=3)$. VCR, vincristine; IWR, the inhibitors of Wnt response. 

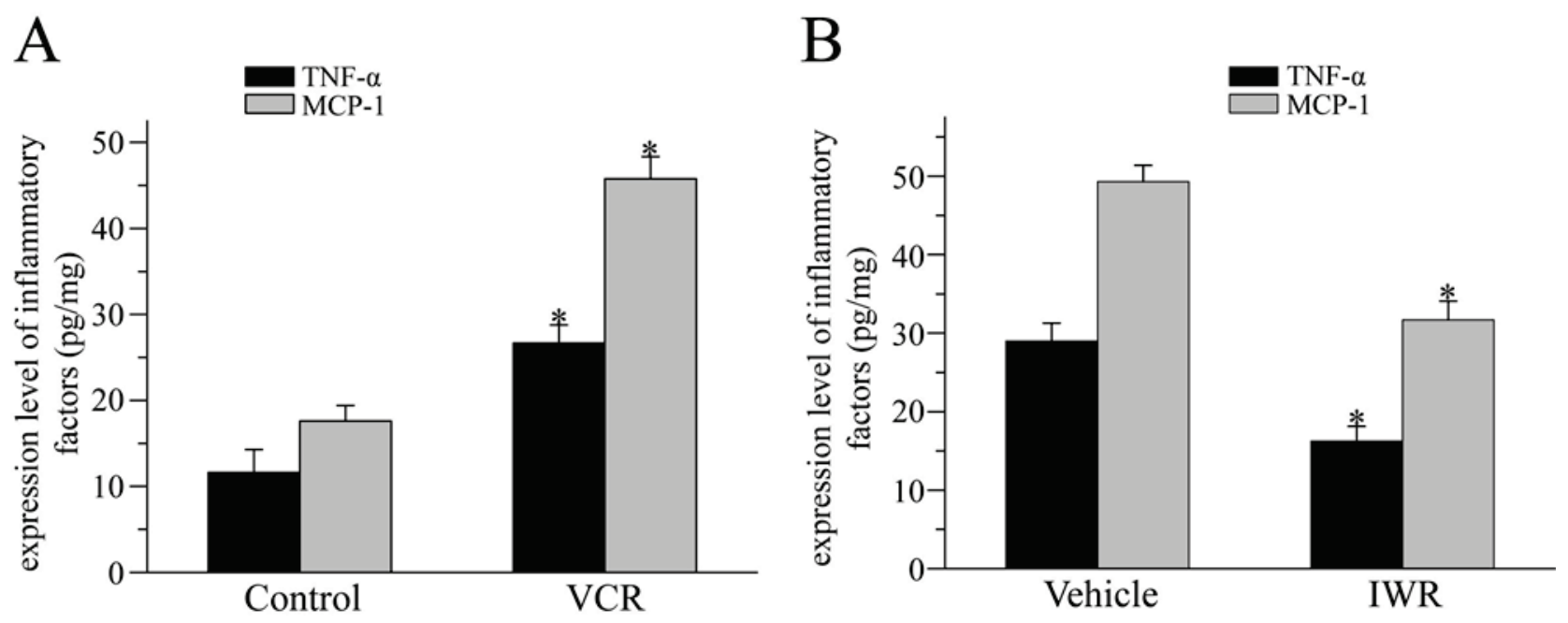

Fig. 4. Blocking Wnt/ $\beta$-catenin signaling suppressed VCR-induced cytokine release. (A): ELISA showed that the protein levels of TNF-a and MCP-1 were increased at day 11 after VCR treatment ( ${ }^{*} P<0.05$, versus Control group; one-way ANOVA with Bonferroni test; $\left.n=4\right)$. (B): TNF- $a$ and MCP-1 protein levels declined after IWR administration at 18 days ( $* P<0.05$ versus Vehicle group; one-way ANOVA with Bonferroni test; $n=4)$. TNF- $a$, tumor necrosis factor- $a$; MCP-1, monocyte chemoattractant protein-1; IWR, the inhibitors of Wnt response.

Wnt/ $\beta$-catenin signaling activation controls the production of TNF- $\alpha$ and MCP-1 in the spinal cord

It has been shown that glial cells release numerous inflammatory cytokines and chemokines that are crucial for chronic pain (Gao and Ji 2010, Watkins et al. 2003). The present study examined the expression of the inflammatory cytokines TNF- $\alpha$ and MCP-1. The ELISA results confirmed that VCR markedly increased the expression of both TNF- $\alpha$ and MCP-1 in the spinal cord at day 11 after VCR administration (Fig. 4). Repetitive administration of IWR significantly inhibited VCR-induced upregulation of TNF- $\alpha$ and MCP-1 at day 18 after VCR injection. These data suggested that $\mathrm{Wnt} / \beta$-catenin signaling activation mediated VCR-induced neuropathic pain possibly through regulating the inflammatory cytokines TNF- $\alpha$ and MCP-1.

Wnt/ $\beta$-catenin signaling inhibition ameliorates VCRinduced neuropathic pain through the MAPK/ERK signaling pathway

Spinal glial cells express MAPKs, which are associated with the regulation of VCR-induced neuropathic pain (Shen et al. 2015). Components of the MAPK signaling pathway, such as ERK, are controlled by Wnt signaling (Yun et al. 2005, Bikkavilli and Malbon 2009). Thus, it was assumed that suppression of Wnt/ $\beta$-catenin signaling by IWR could ameliorate VCR-induced neuropathic pain via MAPK signaling. Our Western blot results showed that VCR enhanced the expression of $\mathrm{p}-\mathrm{ERK} 1 / 2$, which suggested that VCR activated the MAPK/ERK signaling pathway. Furthermore, IWR blocked the VCR-induced p-ERK1/2 increase (Fig. 5).
A

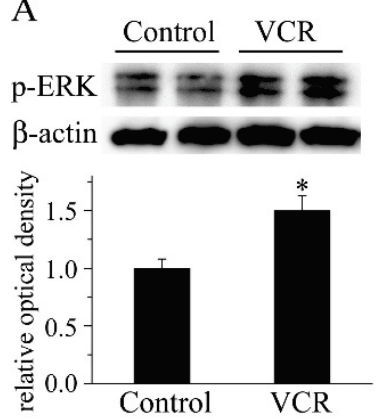

B

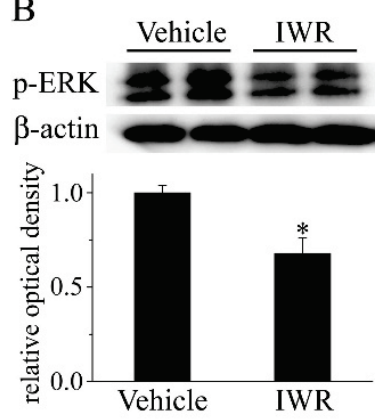

Fig. 5. IWR reduced VCR-induced ERK activation. (A): VCR accelerated the increase in $\mathrm{p}$-ERK in the spinal cord after VCR treatment $(* \mathrm{P}<0.05$ versus Control group; one-way ANOVA with Bonferroni test; $n=3$ ). (B): IWR administration suppressed the enhancement of $p$-ERK that was induced by VCR $(* P<0.05$ versus Vehicle group; one-way ANOVA with Bonferroni test; $n=3$ ). VCR, vincristine; $p$, phosphorylated; IWR, the inhibitors of Wnt response.

\section{Discussion}

Accumulating evidence confirms the presence of aberrant Wnt signaling in certain diseases. For example, Wnt signaling is upregulated in the brains of patients with schizophrenia (Ftouh et al. 2005) and downregulated in the brains of patients with Alzheimer's disease (Nishimura et al. 1999, Caricasole et al. 2004). Wnt3a is 
a well-known activator of different Wnt signaling pathways, and has been extensively examined in the context of development and regeneration of nervous systems (Packard et al. 2002, Fuerer et al. 2008, Liu et al. 2008). The present results indicated that VCR injection augmented Wnt3a expression in the spinal cord. VCR-activated binding of Wnts to Frizzled receptors caused $\beta$-catenin activation and then subsequent activation of the canonical $\mathrm{Wnt} / \beta$-catenin signaling pathway. Furthermore, a Wnt/ $\beta$-catenin signaling pathway inhibitor attenuated VCR-induced neuropathic pain. This suggests that canonical $\mathrm{Wnt} / \beta$-catenin signaling may play critical roles in the pathogenesis of neuropathic pain induced by VCR. To the best of our knowledge, this study is the first to delineate the involvement of $\mathrm{Wnt} / \beta$-catenin signaling in VCR-induced neuropathic pain. However, further studies are required to examine whether the non-canonical pathway is also deregulated in CNP.

Neuropathic pain may be caused by undue inflammation in both the peripheral nervous system and CNS, which may contribute to the initiation and maintenance of persistent pain (Ellis and Bennett 2013). The resultant neuroinflammatory environment induces glial activation in the spinal cord, which may be important in nociception. As peripheral nociception is activated by tissue inflammation and nerve injury, microglial cells activate and release inflammatory cytokines such as IL-6, TNF- $\alpha$ and IL- $1 \beta$, which initiate the process of pain. Microglial cells recruit other microglial cells to propagate the neuroinflammation, which ultimately activates adjacent astrocytes, thus extending the inflammatory boundary and resulting in chronic neuropathic pain (Vallejo et al. 2010). In this study, expression changes of inflammatory mediators such as TNF- $\alpha$ and MCP-1 were examined and used to determine astrocyte and microglial activation, as it is well known that glial cells release increased amounts of inflammatory mediators when they are activated (Jha and Suk, 2014). Our data showed that VCR induced the activation of microglia, astrocytes, TNF- $\alpha$ and MCP-1 in the spinal cord of mice. However, the Wnt/ $\beta$-catenin signaling inhibitor IWR inhibited the activation of astrocytes and microglia induced by VCR, as well as the release of the inflammatory mediators MCP-1 and TNF- $\alpha$ in the spinal cord. Inhibition of the $W n t / \beta$-catenin signaling pathway also prominently alleviates the pathological activation of microglia initiated by partial sciatic nerve ligation, and inhibits chronic constriction injury-induced upregulation of TNF- $\alpha$ (Itokazu et al. 2014, Zhang et al. 2013). Since spinal glial cells play important roles in neuropathic pain (Ji et al. 2013, Zhang et al. 2012), these results suggests that the antinociceptive effect of the aforementioned Wnt/ $\beta$-catenin signaling inhibitor may be partially mediated by the inhibition of glia-mediated neuroinflammation in the spinal cord. Thus Wnt/ $\beta$-catenin signaling may be involved in the pathogenesis of VCR-induced neuropathic pain by regulating neuroinflammation. Another potential mechanism by which the $\mathrm{Wnt} / \beta$-catenin signaling pathway may contribute to CNP is the regulation of synaptic plasticity in pain neural circuits. Brain-derived neurotrophic factor (BDNF) is a main regulator of synaptic plasticity in nociceptive circuits. BDNF upregulation induced by synaptic activity of peripheral pain depends on $\mathrm{Wnt} / \beta$-catenin signaling activation (Zhang et al. 2018). Wnt/ $\beta$-catenin signaling regulates BDNF release from spinal microglia to mediate HIV-associated neuropathic pain (Zhou et al. 2020).

MAPKs (including JNK, ERK and p38) signaling plays vital roles in the development and maintenance of inflammatory and neuropathic pain. Previous studies have indicated that $\mathrm{p}-\mathrm{JNK}$ is induced in spinal astrocytes after spinal nerve injury and CFA-induced inflammatory pain (Gao et al. 2010). P-ERK is induced in sequence in neurons, microglia and astrocytes by spinal nerve ligation and is activated in the astrocytes of the spinal cord by complete Freund's adjuvant (CFA) injection (Weyerbacher et al. 2010). P-p38 is expressed in the microglia of the spinal cord after nerve injury and acute inflammation (Svensson et al. 2003). P-p38 and JNK was significantly increased by the chemotherapy drug bortezomib (BTZ) in the dorsal root ganglion (Liu et al. 2019). Chemotherapeutic VCR activates JNK, ERK and p38 in the spinal cord (Shen et al. 2015). The present study also showed that VCR induced ERK $1 / 2$ activation. In addition, previous studies show that a crosstalk between Wnt/ $\beta$-catenin and MAPK signaling. For example, Wnt3a activates JNK, ERK and p38, and MAPKs regulatesWnt/ $\beta$-catenin signaling (Bikkavilli and Malbon 2009). Since the aforementioned Wnt/ $\beta$-catenin signaling pathway inhibitor reduced the enhancement of VCR-induced upregulation of ERK1/2 and the established mechanical allodynia, our results indicated that $\mathrm{Wnt} / \beta$-catenin signaling inhibitors might alleviate VCR-induced neuropathic pain through inhibition of MAPK/ERK signaling.

It is well-known that a major obstacle during 
cancer treatment is the development of resistance against chemotherapeutic drugs. Previous studies have revealed that inhibition of Wnt signaling prevents chemoresistance. For example, Wnt inhibition downregulates the expression of the DNA repair enzyme O6-methylguanine-DNA methyltransferase (MGMT), which is usually overexpressed in tumors and is associated with the process of chemoresistance (Wickstrom et al. 2015). Suppression of the $\mathrm{Wnt} / \beta$-catenin signaling pathway leads to downregulation of p-glycoprotein and attenuates chemoresistance (Shen et al. 2013). The present study demonstrated that inhibition of $\mathrm{Wnt} / \beta$-catenin signaling alleviated VCR-induced neuropathic pain possibly via suppression of glia-mediated neuroinflammation and MAPK/ERK signaling.

In summary, this study demonstrated that Wnt/ $\beta$-catenin signaling in the spinal cord was crucial for maintaining VCR-induced neuropathic pain and might pave the way to a better understanding of the pathogenesis of VCR-induced neuropathic pain. VCR administration markedly activated $\mathrm{Wnt} / \beta$-catenin signaling, astrocytes, microglia, TNF- $\alpha, \mathrm{MCP}-1$ and the
MAPK/ERK signaling pathway. Blocking Wnt/ $\beta$-catenin signaling by IWR inhibited the established mechanical allodynia as well as the activation of astrocytes, microglia, TNF- $\alpha, \mathrm{MCP}-1$ and MAPK/ERK signaling in the spinal cord. Our results provide evidence for potential interfering with $\mathrm{Wnt} / \beta$-catenin signaling as a method to relieve VCR-induced neuropathic pain.

\section{Conflict of Interest}

There is no conflict of interest.

\section{Acknowledgements}

The present study was supported by grants from the Science and Technology Projects of Guangdong Province (2014A020212507), the Guangdong Medical University Student Innovation Experiment Program (201510571041), the Medical Scientific Research Foundation of Guangdong Province (A2017084), the Scientific Research Fund Project of Guangdong Medical University (Z2016003), the National Science Foundation of Guangdong Province (2017A030307001) and the Project of Enhancing School with Innovation of Guangdong Ocean University (GDOU2013050243).

\section{References}

BIKKAVILLI RK, MALBON CC: Mitogen-activated protein kinases and Wnt/beta-catenin signaling: Molecular conversations among signaling pathways. Commun Integr Biol 246-249, 2009. https://doi.org/10.4161/cib.2.1.7503

CARICASOLE A, COPANI A, CARACI F, ARONICA E, ROZEMULLER AJ, CARUSO A, STORTO M, GAVIRAGHI G, TERSTAPPEN GC, NICOLETTI F: Induction of Dickkopf-1, a negative modulator of the Wnt pathway, is associated with neuronal degeneration in Alzheimer's brain. J Neurosci 24: 6021-6027, 2004. https://doi.org/10.1523/JNEUROSCI.1381-04.2004

CHAPLAN SR, BACH FW, POGREL JW, CHUNG JM, YAKSH TL: Quantitative assessment of tactile allodynia in the rat paw. J Neurosci Methods 53: 55-63, 1994. https://doi.org/10.1016/0165-0270(94)90144-9

CIANI L, SALINAS PC: WNTs in the vertebrate nervous system: from patterning to neuronal connectivity. Nat Rev Neurosci 6: 351-362, 2005. https://doi.org/10.1038/nrn1665

DOUGHERTY PM, CATA JP, BURTON AW, VU K, WENG HR: Dysfunction in multiple primary afferent fiber subtypes revealed by quantitative sensory testing in patients with chronic vincristine-induced pain. J Pain Symptom Manage 33: 166-179, 2007. https://doi.org/10.1016/j.jpainsymman.2006.08.006

ELLIS A, BENNETT DL: Neuroinflammation and the generation of neuropathic pain. Br J Anaesth 111: 26-37, 2013. https://doi.org/10.1093/bja/aet128

FTOUH S, AKBAR MT, HIRSCH SR, DE BELLEROCHE JS: Down-regulation of Dickkopf 3, a regulator of the Wnt signalling pathway, in elderly schizophrenic subjects. J Neurochem 94: 520-530, 2005. https://doi.org/10.1111/j.1471-4159.2005.03239.x

FUERER C, NUSSE R, TEN BERGE D: Wnt signalling in development and disease. Max Delbruck Center for Molecular Medicine meeting on Wnt signaling in Development and Disease. EMBO Rep 9: 134-138, 2008. https://doi.org/10.1038/sj.embor.7401159 
GAO YJ, JI RR: Targeting astrocyte signaling for chronic pain. Neurotherapeutics 7: 482-493, 2010. https://doi.org/10.1016/j.nurt.2010.05.016

GAO YJ, XU ZZ, LIU YC, WEN YR, DECOSTERD I, JI RR: The c-Jun N-terminal kinase 1 (JNK1) in spinal astrocytes is required for the maintenance of bilateral mechanical allodynia under a persistent inflammatory pain condition. Pain 148: 309-319, 2010. https://doi.org/10.1016/j.pain.2009.11.017

GRIGORYAN T, WEND P, KLAUS A, BIRCHMEIER W: Deciphering the function of canonical Wnt signals in development and disease: conditional loss- and gain-of-function mutations of beta-catenin in mice. Genes Dev 22: 2308-2341, 2008. https://doi.org/10.1101/gad.1686208

HU CY, ZHANG GP, ZHAO YT: Fucoidan attenuates the existing allodynia and hyperalgesia in a rat model of neuropathic pain. Neurosci Lett 571: 66-71, 2014. https://doi.org/10.1016/j.neulet.2014.04.030

ITOKAZU T, HAYANO Y, TAKAHASHI R, YAMASHITA T: Involvement of Wnt/beta-catenin signaling in the development of neuropathic pain. Neurosci Res 79: 34-40, 2014. https://doi.org/10.1016/j.neures.2013.12.002

JHA MK, SUK K: Management of glia-mediated neuroinflammation and related patents. Recent Pat Inflamm Allergy Drug Discov 8: 118-124, 2014. https://doi.org/10.2174/1872213X08666140619105915

JI XT, QIAN NS, ZHANG T, LI JM, LI XK, WANG P, ZHAO DS, HUANG G, ZHANG L, FEI Z, JIA D, NIU L: Spinal astrocytic activation contributes to mechanical allodynia in a rat chemotherapy-induced neuropathic pain model. PloS one 8: e60733, 2013. https://doi.org/10.1371/journal.pone.0060733

KIGUCHI N, MAEDA T, KOBAYASHI Y, KISHIOKA S: Up-regulation of tumor necrosis factor-alpha in spinal cord contributes to vincristine-induced mechanical allodynia in mice. Neurosci Lett 445: 140-143, 2008. https://doi.org/10.1016/j.neulet.2008.09.009

LIU D, SUN M, XU D, MA X, GAO D, YU H: Inhibition of TRPA1 and IL-6 signal alleviates neuropathic pain following chemotherapeutic bortezomib. Physiol Res 68: 845-855, 2019. https://doi.org/10.33549/physiolres.934015

LIU Y, WANG X, LU CC, KERMAN R, STEWARD O, XU XM, ZOU Y: Repulsive Wnt signaling inhibits axon regeneration after CNS injury. J Neurosci 28: 8376-8382, 2008. https://doi.org/10.1523/JNEUROSCI.1939$\underline{08.2008}$

MACDONALD BT, TAMAI K, HE X: Wnt/beta-catenin signaling: components, mechanisms, and diseases. Dev Cell 17: 9-26, 2009. https://doi.org/10.1016/j.devcel.2009.06.016

MARCHETTI B, PLUCHINO S: Wnt your brain be inflamed? Yes, it Wnt! Trends Mol Med 19: 144-156, 2013. https://doi.org/10.1016/j.molmed.2012.12.001

NISHIMURA M, YU G, LEVESQUE G, ZHANG DM, RUEL L, CHEN F, MILMAN P, HOLMES E, LIANG Y, KAWARAI T, JO E, SUPALA A, ROGAEVA E, XU DM, JANUS C, LEVESQUE L, BI Q, DUTHIE M, R OZMAHEL R, MATTILA K, LANNFELT L, WESTAWAY D, MOUNT HT, WOODGETT J, ST GEORGEHYSLOP P, et al. Presenilin mutations associated with Alzheimer disease cause defective intracellular trafficking of beta-catenin, a component of the presenilin protein complex. Nat Med 5: 164-169, 1999. https://doi.org/10.1038/5526

PACKARD M, KOO ES, GORCZYCA M, SHARPE J, CUMBERLEDGE S, BUDNIK V: The Drosophila Wnt, wingless, provides an essential signal for pre- and postsynaptic differentiation. Cell 111: 319-330, 2002. https://doi.org/10.1016/S0092-8674(02)01047-4

PARK M, SHEN K: WNTs in synapse formation and neuronal circuitry. EMBO J 31: 2697-2704, 2012. https://doi.org/10.1038/emboj.2012.145

RESHAM K, SHARMA SS: Pharmacologic inhibition of porcupine, disheveled, and beta-catenin in Wnt signaling pathway ameliorates diabetic peripheral neuropathy in rats. J Pain 19: 30717-30725, 2019. https://doi.org/10.1016/j.jpain.2019.04.010

SHEN DY, ZHANG W, ZENG X, LIU CQ: Inhibition of Wnt/beta-catenin signaling downregulates P-glycoprotein and reverses multi-drug resistance of cholangiocarcinoma. Cancer Sci 104: 1303-1308, 2013. https://doi.org/10.1111/cas.12223

SHEN Y, ZHANG ZJ, ZHU MD, JIANG BC, YANG T, GAO YJ: Exogenous induction of HO-1 alleviates vincristineinduced neuropathic pain by reducing spinal glial activation in mice. Neurobiol Dis 79: 100-110, 2015. https://doi.org/10.1016/j.nbd.2015.04.012 
SHI Y, SHU J, GELMAN BB, LISINICCHIA JG, TANG SJ: Wnt signaling in the pathogenesis of human HIVassociated pain syndromes. J Neuroimmune Pharmacol 8: 956-964, 2013. https://doi.org/10.1007/s11481-0139474-4

SPEESE SD, BUDNIK V: Wnts: up-and-coming at the synapse. Trends Neurosci 30: 268-275, 2007. https://doi.org/10.1016/j.tins.2007.04.003

SVENSSON CI, MARSALA M, WESTERLUND A, CALCUTT NA, CAMPANA WM, FRESHWATER JD, CATALANO R, FENG Y, PROTTER AA, SCOTT B, YAKSH TL: Activation of p38 mitogen-activated protein kinase in spinal microglia is a critical link in inflammation-induced spinal pain processing. J Neurochem 86: 1534-1544, 2003. https://doi.org/10.1046/j.1471-4159.2003.01969.x

TANG J, JI Q, JIN L, TIAN M, ZHANG LD, LIU XY: Secreted frizzled-related protein 1 regulates the progression of neuropathic pain in mice following spinal nerve ligation. J Cell Physiol 233: 5815-5822, 2018. https://doi.org/10.1002/jcp.26358

VALLEJO R, TILLEY DM, VOGEL L, BENYAMIN R: The role of glia and the immune system in the development and maintenance of neuropathic pain. Pain Pract 10: 167-184, 2010. https://doi.org/10.1111/j.15332500.2010.00367.x

WATKINS LR, MILLIGAN ED, MAIER S: Glial proinflammatory cytokines mediate exaggerated pain states: implications for clinical pain. Adv Exp Med Biol 521: 1-21, 2003.

WEYERBACHER AR, XU Q, TAMASDAN C, SHIN SJ, INTURRISI CE: N-Methyl-D-aspartate receptor (NMDAR) independent maintenance of inflammatory pain. Pain 148: 237-246, 2010. https://doi.org/10.1016/j.pain.2009.11.003

WICKSTROM M, DYBERG C, MILOSEVIC J, EINVIK C, CALERO R, SVEINBJORNSSON B, SANDEN E, DARABI A, SIESJO P, KOOL M, KOGNER P, BARYAWNO N, JOHNSEN JI: Wnt/beta-catenin pathway regulates MGMT gene expression in cancer and inhibition of Wnt signalling prevents chemoresistance. Nat Commun 6: 8904, 2015. https://doi.org/10.1038/ncomms9904

WU WP, XU XJ, HAO JX: Chronic lumbar catheterization of the spinal subarachnoid space in mice. J Neurosci Methods 133: 65-69, 2004. https://doi.org/10.1016/j.jneumeth.2003.09.015

YUAN S, SHI Y, TANG SJ: Wnt signaling in the pathogenesis of multiple sclerosis-associated chronic pain. J Neuroimmune Pharmacol 7: 904-913, 2012. https://doi.org/10.1007/s11481-012-9370-3

YUN MS, KIM SE, JEON SH, LEE JS, CHOI KY: Both ERK and Wnt/beta-catenin pathways are involved in Wnt3a-induced proliferation. J Cell Sci 118: 313-322, 2005. https://doi.org/10.1242/jcs.01601

ZHANG H, YOON SY, DOUGHERTY PM: Evidence that spinal astrocytes but not microglia contribute to the pathogenesis of Paclitaxel-induced painful neuropathy. J Pain 13: 293-303, 2012. https://doi.org/10.1016/j.jpain.2011.12.002

ZHANG W, SHI Y, PENG Y, ZHONG L, ZHU S, ZHANG W, TANG SJ: Neuron activity-induced Wnt signaling up-regulates expression of brain-derived neurotrophic factor in the pain neural circuit. J Biol Chem 293: 15641-15651, 2018. https://doi.org/10.1074/jbc.RA118.002840

ZHANG YK, HUANG ZJ, LIU S, LIU YP, SONG AA, SONG XJ: WNT signaling underlies the pathogenesis of neuropathic pain in rodents. J Clin Invest 123: 2268-2286, 2013. https://doi.org/10.1172/JCI65364

ZHOU X, TAO L, ZHAO M, WU S, OBENG E, WANG D, ZHANG W: Wnt/beta-catenin signaling regulates brainderived neurotrophic factor release from spinal microglia to mediate HIV1 gp120-induced neuropathic pain. Mol pain 16: 1744806920922100, 2020. https://doi.org/10.1177/1744806920922100 